\title{
Thermal Performance of Solar Air Heater Having Absorber Plate with V-Down Discrete Rib Roughness for Space-Heating Applications
}

\author{
Rajendra Karwa and V. Srivastava \\ Department of Mechanical Engineering, Faculty of Engineering \& Architecture, Jai Narain Vyas University, \\ Jodhpur 342 011, Rajasthan, India \\ Correspondence should be addressed to Rajendra Karwa; karwa_r@yahoo.com
}

Received 15 August 2012; Revised 29 October 2012; Accepted 30 October 2012

Academic Editor: Zuhal Oktay

Copyright (C) 2013 R. Karwa and V. Srivastava. This is an open access article distributed under the Creative Commons Attribution License, which permits unrestricted use, distribution, and reproduction in any medium, provided the original work is properly cited.

\begin{abstract}
The paper presents results of thermal performance analysis of a solar air heater with v-down discrete rib roughness on the air flow side of the absorber plate, which supplies heated air for space heating applications. The air heater operates in a closed loop mode with inlet air at a fixed temperature of $295 \mathrm{~K}$ from the conditional space. The ambient temperature varied from $278 \mathrm{~K}$ to $288 \mathrm{~K}$ corresponding to the winter season of Western Rajasthan, India. The results of the analysis are presented in the form of performance plots, which can be utilized by a designer for calculating desired air flow rate at different ambient temperature and solar insolation values.
\end{abstract}

\section{Introduction}

Flat plate solar air heaters have been employed for space heating, drying, and similar industrial applications requiring heated air at low to moderate temperatures. The thermal efficiency of a solar air heater (collector) is a function of many design and operating parameters. Convective heat transfer coefficient between the absorber plate and air flowing through the collector duct is one of the key parameters.

Artificial roughness on heat transferring surface of asymmetrically heated high aspect ratio rectangular ducts, modeled as solar air heater ducts, has been shown to significantly enhance the heat transfer coefficient with minimum pressure loss penalty because the roughness creates turbulence near the heat transferring surface only [1-7]. Thus such roughness can be used on the air flow side of the absorber plate of the solar air heaters as shown in Figure 1(a) for the improvement of their thermal efficiency.

Figure 1(b) depicts the basic roughness geometries compiled by Karwa et al. [8], which includes different rib arrangements, such as transverse, angled, continuous, and discrete, in v-pattern for ribs of different shapes (circular, square, chamfered, wedge, etc.), and expanded metal wire mesh. Artificial roughness on a heat transferring surface creates local wall turbulence due to a complex flow structure depending on the shape and arrangement of the ribs and hence the degree of the heat transfer enhancement in both the heat transfer coefficient and friction factor also varies with the roughness type.

Heat transfer enhancement in the case of the inclined or the v-pattern ribs has been reported to be higher than the transverse ribs [9]. The enhancement in the case of the transverse ribs (at $p / e \geq 7$ ) occurs only due to the flow, separated at the ribs, reattaching between the ribs while it has been attributed both to the reattachment effect and the secondary flow of the air induced by the rib inclination in the case of inclined and v-pattern ribs [7,9] as depicted in Figure 2. The secondary flow (movement of heated air in contact with the plate surface) is along the plate surface to the side wall in the case of the inclined ribs. This exposes the heated plate to a relatively lower temperature air of the axial or primary flow over the ribs. In the case of v-down ribs, there are two contradictory effects: the secondary flow is towards the central axis where it interacts with the axial flow 

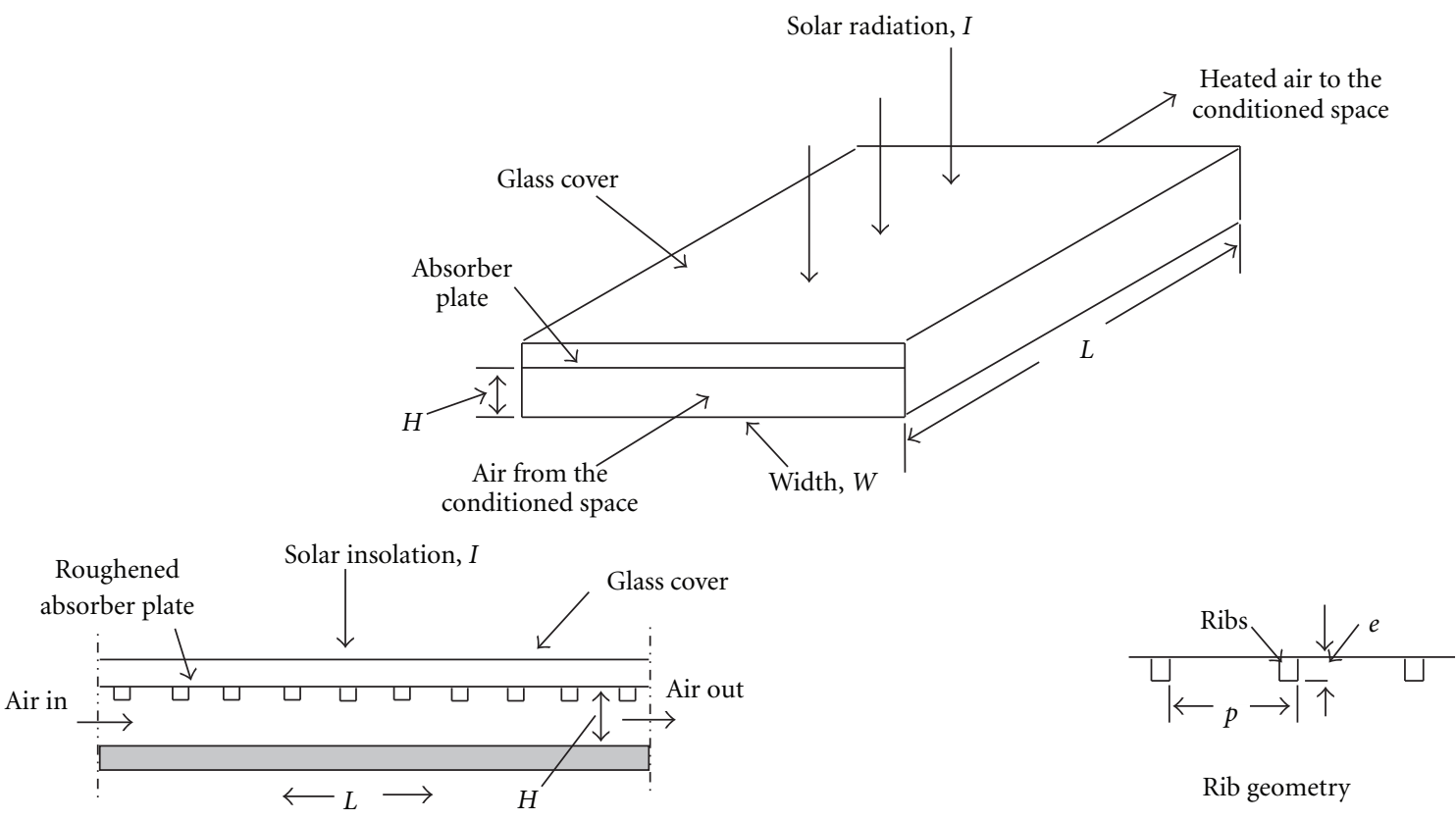

Rib geometry

(a)

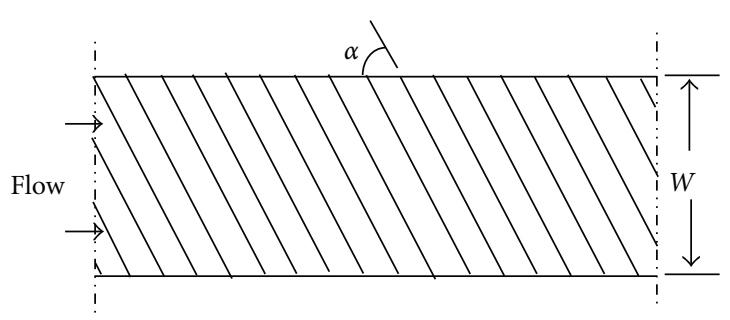

(i) Circular cross-section wire inclined to flow $[1,2]$

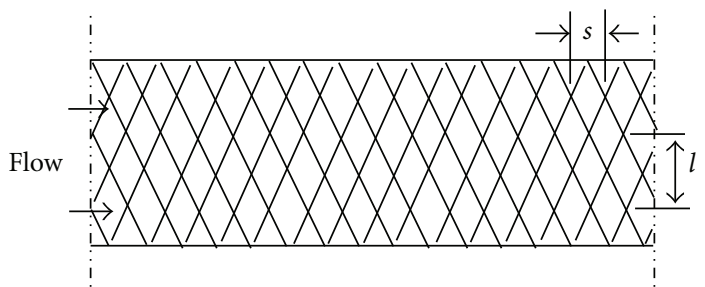

(ii) Expanded metal wire mesh [3]

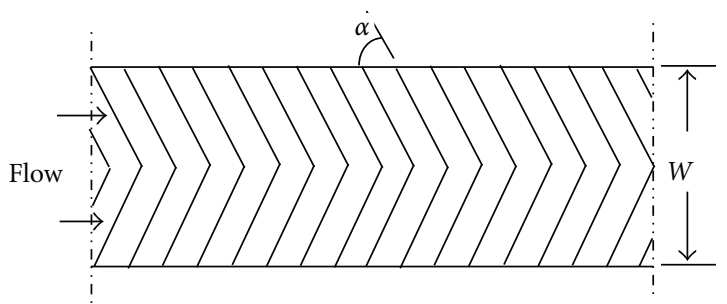

(iii) Circular cross-section wire in v-pattern [6]

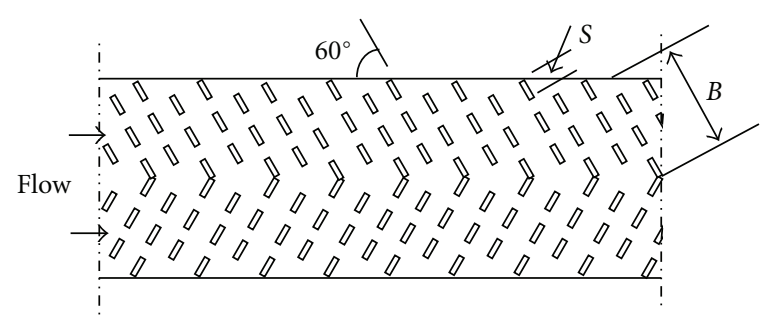

(iv) V-discrete rib roughness [7]

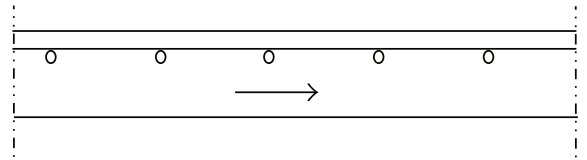

(v) Circular cross-section wire as ribs $[1,2,6]$

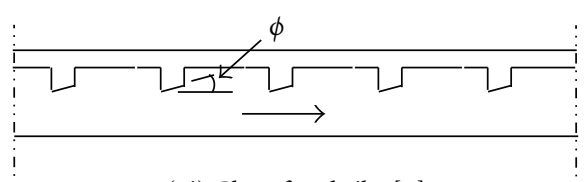

(vi) Chamfered ribs [4]

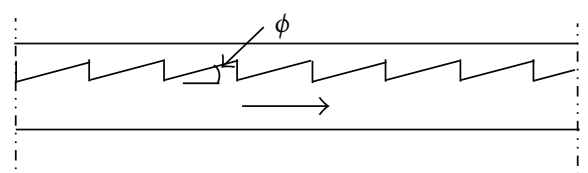

(vii) Wedge shaped roughness [5]

(b)

FIGURE 1: (a) Schematic diagram and longitudinal section of a solar air heater with roughened absorber plate, (b) roughness for solar air heater ducts: (i)-(iv) plan view, (v)-(vii) longitudinal section [8]. 


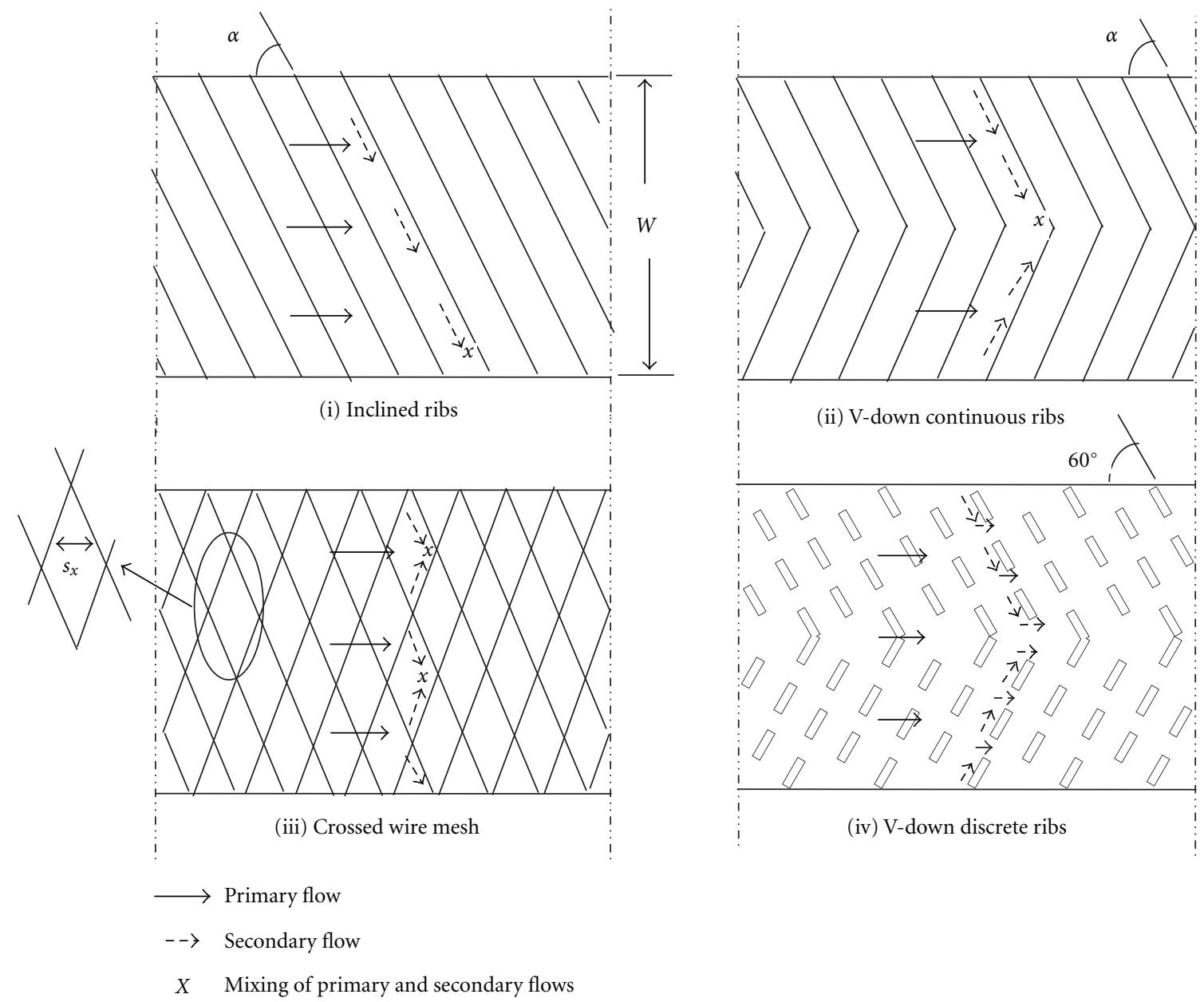

Figure 2: Effect of rib orientation on the flow [8].

(at $x$ in Figure 2) creating additional turbulence leading to the increase in the heat transfer rate while the rise in temperature of the axial flow air, just above the ribs in the central region due to the mixing of the secondary flow, reduces the heat transfer rate. For the discrete ribs, the heated air moving as secondary flow mixes with the primary air after only a short distance movement leading to a better mixing of the heated air near the plate with the colder primary air. In the case of crossed wire mesh, the flow structure is quite complex. For example, the axial distance $s_{x} / e$ between the rib elements of the mesh of R. P. Saini and J. S. Saini [3] varies from 0 to 25. The primary flow over the mesh portion with $7<s_{x} / e \leq 25$ causes enhancement due to the reattachment effect, while the flow between $0<s_{x} / e \leq 7$ contributes poorly due to the vortex flow. The secondary flow mainly occurs along the rib elements where $s_{x} / e$ is greater than 7 and thus is likely to be less strong. The secondary flow air, here also, mixes after a short distance movement with the primary flow over the ribs at $x$.

Various studies report different degrees of enhancements in heat transfer and friction factor because of the difference in the flow structure as discussed above. Thus the preference of any roughness type must be based on the objective of heat transfer enhancement with minimum pressure loss penalty and hence a thermo-hydraulic performance analysis is desired. Based on the criterion of equal pumping power, Karwa et al. [8] carried out a comparison of different roughness geometries depicted in Figure 1(b) to find out the preferred type of roughness for the absorber plate of a solar air heater. They have recommended discrete rib roughness geometry of Karwa et al. [7] for applications such as space heating requiring heated air with temperature rise of the order of $15^{\circ} \mathrm{C}-25^{\circ} \mathrm{C}$.

Karwa and Chauhan [10] carried out studies on thermal and effective efficiencies of solar air heaters, with open loop operation, having $60^{\circ} \mathrm{v}$-down discrete rectangular crosssection repeated rib roughness on the air flow side of the absorber plate using a mathematical model, which was validated against experimental data. The efficiency of the solar air heater is defined as

$$
\eta=\frac{Q}{I A}=\frac{M c_{p} \Delta t}{I A}=\frac{G c_{p} \Delta t}{I},
$$

where $Q$ is the useful heat gain, $I$ is the incident solar radiation intensity on the collector plane, $A$ is the area of solar air heater receiving solar radiation, $\Delta t$ is the rise in the 
temperature of the air, and $G(=M / A)$ is the air flow rate per unit area of the absorber plate.

The effective efficiency $\eta_{e}$, in their study, is based on the net gain after taking account of the pumping power:

$$
\eta_{e}=\frac{[(\mathrm{Q}+P)-P / C]}{I A},
$$

where $C$ is a conversion factor used for calculating equivalent thermal energy for obtaining the pumping power. It is a product of the efficiencies of the fan, electric motor, transmission, and thermoelectric conversion.

They concluded that the preferred relative roughness height is 0.07 for a solar air heater to be used for space heating applications, where the air flow rate per unit area of the absorber plate is on the lower side $\left(G \leq 0.45 \mathrm{kgs}^{-1} \mathrm{~m}^{-2}\right)$.

\section{Objective}

From the literature review presented above, it can be inferred that roughened duct solar air heaters can provide enhanced thermal and thermo-hydraulic performance. For low mass flow rates applicable to space heating applications, the previous studies have established that the $60^{\circ} \mathrm{v}$-down discrete rib roughness of Karwa et al. [7] is the preferred one. However, results of studies on the performance of such roughened solar air heaters operating in a closed loop for space heating applications are not available in the open literature. Hence, the present study has been planned to carry out performance studies on solar air heaters with $60^{\circ} \mathrm{v}$-down discrete rib roughness of Karwa et al. [7] on the air flow side of absorber plate for closed loop operation, where the inlet temperature of the air coming from the conditional space is constant. The analysis in the present study will be carried out by suitably modifying the mathematical model of Karwa and Chauhan [10].

\section{Mathematical Model for Thermal Performance Prediction}

The model used by Karwa and Chauhan [10] is based on the nonlinear mathematical model presented for a smooth duct solar air heater by Karwa et al. [11], which was suitably modified by them for the study of roughened solar air heaters in their work. This model calculates the useful heat gain from the iterative solution of basic heat transfer equations of top loss and equates the same with the convective heat transfer from the absorber plate to the air using proper heat transfer correlations for the roughened and smooth duct air heaters. This model has also been modified by them to estimate the collector back loss from the iterative solution of the heat balance equation for the back surface for greater accuracy. The edge loss has been calculated from the equation suggested by Klein [12].

Figure 3(a) depicts the schematic diagram of a solar air heater and its longitudinal section along with plan of the roughened absorber plate having $60^{\circ} \mathrm{v}$-down discrete rib roughness of Karwa et al. [7].
The heat balance on a solar air heater gives the distribution of incident solar radiation $I$ into useful heat gain $Q$ and various heat losses as depicted in Figure 3(b). The useful heat gain or heat collection rate of the collector is

$$
Q=A I(\tau \alpha)-Q_{L}=A\left[I(\tau \alpha)-U_{L}\left(T_{p}-T_{a}\right)\right]
$$

where $A$ is the area of the absorber plate, $(\tau \alpha)$ is the transmittance-absorptance product of the glass coverabsorber plate combination. The overall heat loss $Q_{L}$ from the air heater is a sum of the losses from top $Q_{t}$, back $Q_{b}$, and edge $Q_{e}$ of the collector. The overall loss coefficient $U_{L}$ is defined as

$$
U_{L}=\frac{Q_{L}}{\left[A\left(T_{p}-T_{a}\right)\right]}
$$

where $T_{p}$ is mean absorber plate temperature and $T_{a}$ is ambient temperature.

The collected heat is transferred to the air to be heated. Thus,

$$
\mathrm{Q}=M c_{p}\left(T_{o}-T_{i}\right)=G A c_{p}\left(T_{o}-T_{i}\right) .
$$

The heat transfer coefficient $h$ between the air and absorber plate is determined from appropriate heat transfer coefficient correlation. The useful heat gain in terms of the heat transfer coefficient $h$ is

$$
Q=h A\left(T_{p}-T_{f m}\right)
$$

where $T_{f m}$ is the mean temperature of air in the air heater duct.

3.1. Top Loss. The top loss $Q_{t}$ from the collector has been calculated from the iterative solution of basic heat transfer equations as detailed below.

Heat transfer from the absorber plate at mean temperature $T_{p}$ to the inner surface of the glass cover at temperature $T_{g i}$ takes place by radiation and convection. Hence,

$$
Q_{t p g}=A\left[\sigma\left(T_{p}^{4}-T_{g i}^{4}\right)\left(\frac{1}{\varepsilon_{p}}+\frac{1}{\varepsilon_{g}}-1\right)^{-1}+h_{p g}\left(T_{p}-T_{g i}\right)\right] .
$$

The heat transfer through the glass cover of thickness $\delta_{g}$ by conduction is

$$
Q_{t g}=\frac{k_{g} A\left(T_{g i}-T_{g o}\right)}{\delta g}
$$

where $k_{g}$ is the thermal conductivity of the glass and $T_{g o}$ is temperature of the outer surface of the glass cover.

From the outer surface of the glass cover, the heat is rejected by radiation to the sky at temperature $T_{s}$ and by convection to the ambient air. Hence, 


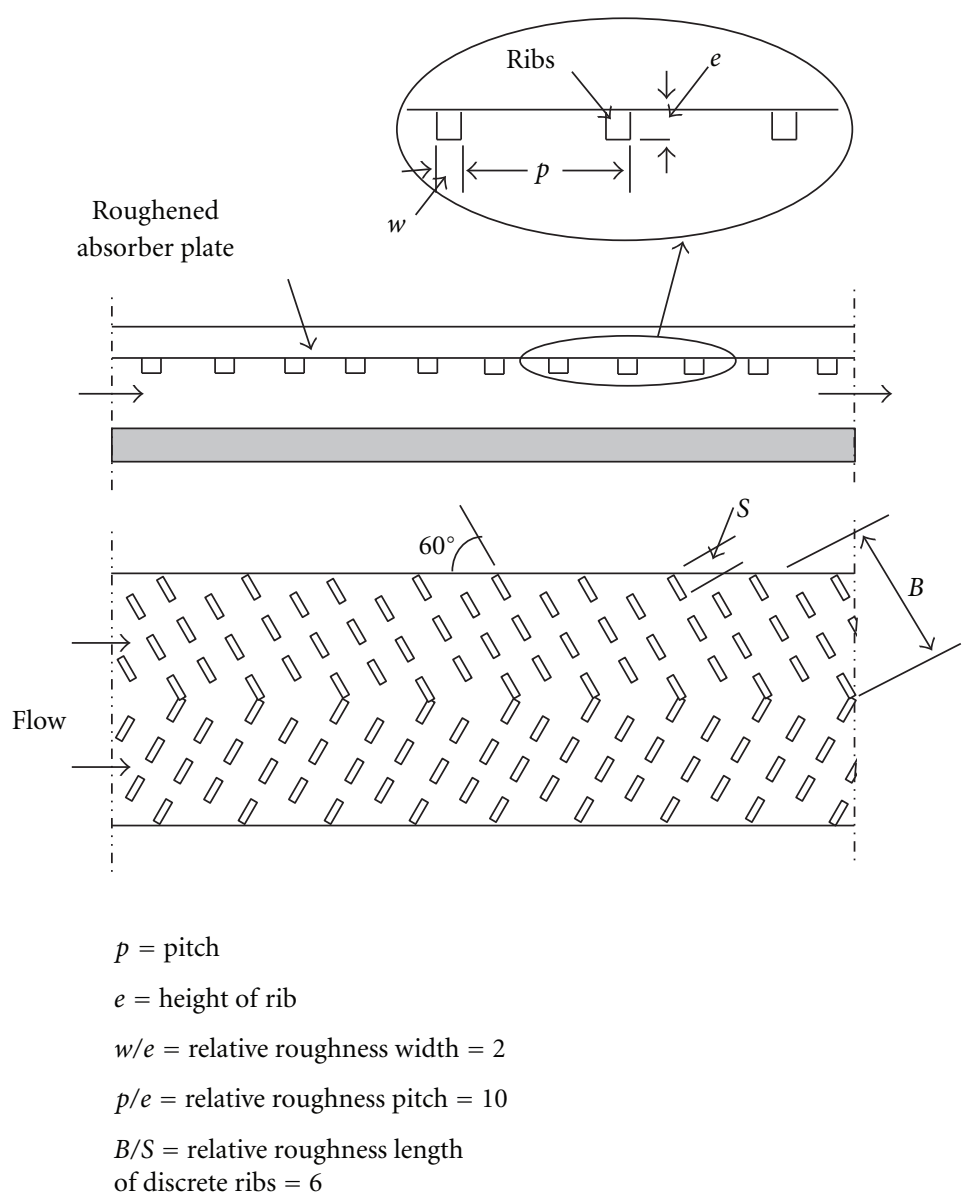

(a)

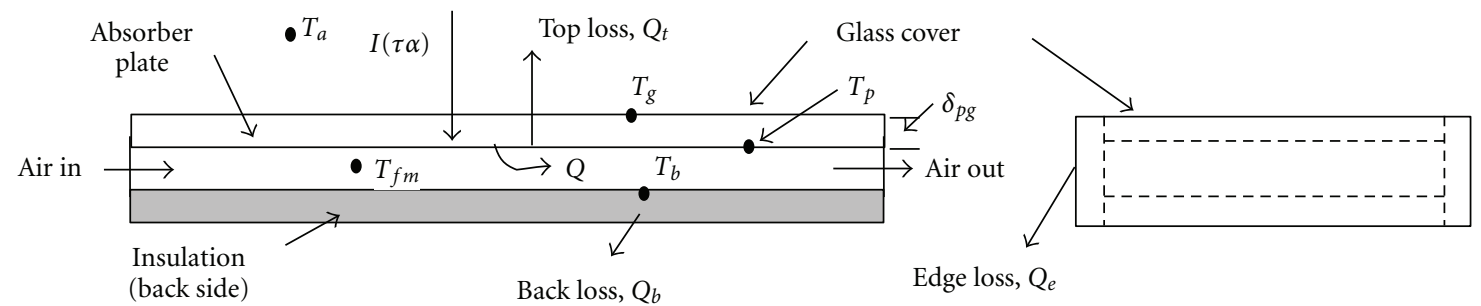

(b)

FIGURE 3: (a) Longitudinal section of the roughened duct air heater with plane view of absorber plate having $60^{\circ} \mathrm{v}$-down discrete rib roughness; (b) heat balance.

$$
Q_{t g o}=A\left[\sigma \varepsilon_{g}\left(T_{g o}^{4}-T_{s}^{4}\right)+h_{w}\left(T_{g o}-T_{a}\right)\right]
$$

where $h_{w}$ is the wind heat transfer coefficient.

In the equilibrium, $Q_{t p g}=Q_{t g}=Q_{t g o}=Q_{t}$.

The sky temperature $T_{s}$, in $(7 \mathrm{c})$, is a function of many parameters. Some studies assume the sky temperature to be equal to the ambient temperature because it is difficult to make a correct estimate of it, while others estimate it using different correlations. One such widely used formula for clear sky is due to Swinbank [13], which is

$$
T_{s}=0.0552 T_{a}^{1.5}
$$

For the estimate of the convective heat transfer coefficient between the absorber plate and glass cover $h_{p g}$ the threeregion correlation of Buchberg et al. [14] has been used:

$$
\mathrm{Nu}=1+1.446\left(1-\frac{1708}{\mathrm{Ra}^{\prime}}\right)^{+} \text {for } 1708 \leq \mathrm{Ra}^{\prime} \leq 5900
$$

(the + bracket goes to zero when negative),

$$
\begin{gathered}
\mathrm{Nu}=0.229\left(\mathrm{Ra}^{\prime}\right)^{0.252} \text { for } 5900<\mathrm{Ra}^{\prime} \leq 9.23 \times 10^{4}, \\
\mathrm{Nu}=0.157\left(\mathrm{Ra}^{\prime}\right)^{0.285} \text { for } 9.23 \times 10^{4}<\mathrm{Ra}^{\prime} \leq 10^{6},
\end{gathered}
$$


where $\mathrm{Ra}^{\prime}=(\mathrm{Ra} \cos \beta)$ is the Rayleigh number for the inclined air layers. The Rayleigh number for the natural convection flow between parallel plates (absorber plate and glass cover) is given by

$$
\mathrm{Ra}=\mathrm{Gr} \operatorname{Pr}=\left[\frac{g\left(T_{p}-T_{g i}\right) \delta_{p g}^{3}}{T_{m p g} \nu_{m p g}^{2}}\right] \operatorname{Pr},
$$

where $\delta_{p g}$ is the gap between the absorber plate and glass cover.

3.2. Back and Edge Losses. The back loss from the collector, refer Figure 3(b), has been calculated from the following equation:

$$
Q_{b}=\frac{A\left(T_{b}-T_{a}\right)}{\left(\delta / k_{i}+1 / h_{w}\right)},
$$

where $\delta$ is insulation thickness and $k_{i}$ is the thermal conductivity of the insulating material.

Heat transfer by radiation from the heated absorber plate to the duct bottom surface is

$$
Q_{p b}=\sigma\left(T_{p}^{4}-T_{b}^{4}\right)\left(\frac{1}{\varepsilon_{p i}}+\frac{1}{\varepsilon_{b}}-1\right)^{-1} .
$$

The heated bottom surface at temperature $T_{b}$ transfers heat to the surroundings through the back insulation and to the air flowing through the duct at mean temperature $T_{f m}$, that is,

$$
Q_{b a}=\frac{T_{b}-T_{a}}{\left(\delta / k_{i}+1 / h_{w}\right)}+h\left(T_{b}-T_{f m}\right)
$$

The absorber plate inner surface and duct bottom surface long wave emissivity values $\varepsilon_{p i}$ and $\varepsilon_{b}$ in (11b) have been assumed to be 0.9 . The heat balance for the back surface gives $Q_{p b}=Q_{b a}$. The temperature of the duct bottom surface $T_{b}$ has been estimated from the iterative solution of this heat balance equation.

For the edge loss estimate, the following empirical equation suggested by Klein [12] has been used:

$$
Q_{e}=0.5 A_{e}\left(T_{p}-T_{a}\right),
$$

where $A_{e}$ is the area of the edge of the air heater transferring heat to the surroundings.

The outlet air temperature has been estimated from

$$
T_{o}=T_{i}+\frac{Q}{M c_{p}} .
$$

The mean plate temperature equation in terms of heat removal factor $F_{R}$ and efficiency factor $F^{\prime}$ is

$$
T_{p m}=T_{i}+\frac{Q\left(1-F_{R}\right)}{A U_{L} F_{R}} .
$$

The parameter $F_{R}$ in the above equation is given by the following relation:

$$
F_{R}=\left(\frac{G c_{p}}{U_{L}}\right)\left[1-\exp \left(-\frac{F^{\prime} U_{L}}{G c_{p}}\right)\right],
$$

where $F^{\prime}$ in the above equation is defined as

$$
F^{\prime}=\left(1+\frac{U_{L}}{h}\right)^{-1} .
$$

The outlet temperature of air in terms of $F_{R}$ is

$$
T_{o}=T_{i}+F_{R} \frac{\left[I(\tau \alpha)-U_{L}\left(T_{i}-T_{a}\right)\right]}{G c_{p}} .
$$

The mean air temperature equation in terms of $F_{R}$ and $F^{\prime}$ is

$$
T_{f m}=T_{i}+\frac{Q\left(1-F_{R} / F^{\prime}\right)}{A U_{L} F_{R}} .
$$

Equations (14) and (17) have been used for the crosscheck of the values of temperatures $T_{p}$ and $T_{o}$ calculated from (6) and (13), respectively.

Knowing that the accuracy of the results of the performance analysis strongly depends on the use of appropriate heat transfer and friction factor correlations for the solar air heater ducts, the model has taken extra care and efforts to select them.

For the asymmetrically heated high aspect ratio rectangular ducts of smooth duct solar air heater, Karwa et al. [11] used the following correlation of Chen in [15] for the apparent friction factor in the laminar regime:

$$
f_{\text {app }}=\frac{24}{\operatorname{Re}}+\frac{(0.64+38 / \operatorname{Re}) D_{h}}{4 L} .
$$

The last term in the equation takes account of the increase in the friction factor in the entrance region of the duct.

The following heat transfer correlation from Hollands and Shewen [16] for the thermally developing laminar flow for the smooth duct has been used:

$$
\mathrm{Nu}=5.385+0.148 \operatorname{Re}\left(\frac{H}{L}\right) \quad \text { for } \operatorname{Re}<2550 .
$$

The friction factor correlation suggested by Bhatti and Shah [17] for the transition to turbulent flow regime in rectangular cross-section smooth duct $(0 \leq H / W \leq 1)$ is

$$
f=\left(1.0875-\frac{0.1125 H}{W}\right) f_{o},
$$

where

$$
\begin{gathered}
f_{o}=0.0054+2.3 \times 10^{-8} \operatorname{Re}^{1.5}, \quad \text { for } 2100 \leq \operatorname{Re} \leq 3550, \\
f_{o}=1.28 \times 10^{-3}+0.1143 \mathrm{Re}^{-0.311}, \quad \text { for } 3550<\operatorname{Re} \leq 10^{7} .
\end{gathered}
$$


The reported uncertainty is $\pm 5 \%$ in the predicted friction factor from the above correlation.

Considering the entrance region effect, the apparent friction factor has been determined from the following relation for flat parallel plate duct in the turbulent flow regime [17]:

$$
f_{\text {app }}=f+0.0175\left(\frac{D_{h}}{L}\right) \text {. }
$$

The Nusselt number correlations used for the transition and turbulent flow regimes from Hollands and Shewen [16] are:

$$
\mathrm{Nu}=4.4 \times 10^{-4} \mathrm{Re}^{1.2}+9.37 \mathrm{Re}^{0.471}\left(\frac{H}{L}\right)
$$

for $2550 \leq \operatorname{Re} \leq 10^{4}$ (transition flow regime),

$$
\mathrm{Nu}=0.03 \mathrm{Re}^{0.74}+0.788 \operatorname{Re}^{0.74}\left(\frac{H}{L}\right)
$$

for $10^{4}<\operatorname{Re} \leq 10^{5}$ (early turbulent flow regime).

The uncertainty of an order of $5-6 \%$ in the predicted Nusselt number has been expected [11]. As suggested by Karwa et al. [11], the laminar regime has been assumed in the model up to $\mathrm{Re}=2800$. The inconsistency of the predicted Nusselt number and friction factor values from the correlations presented above is about $5 \%$ at the laminartransition interface [11].

The friction factor and heat transfer correlations for the $60^{\circ} \mathrm{V}$-down discrete rectangular cross-section repeated rib roughness used for the roughened duct solar air heater are [7]

$$
\begin{aligned}
& R=6.06\left(e^{+}\right)^{0.045}, \quad \text { for } 15 \leq e^{+} \leq 75 \\
& g=15.69\left(e^{+}\right)^{-0.2}, \quad \text { for } 15 \leq e^{+}<25 \\
& g=4.1\left(e^{+}\right)^{0.217}, \quad \text { for } 25 \leq e^{+} \leq 75
\end{aligned}
$$

where $R$ is termed as roughness function and $e^{+}$is the roughness Reynolds number. These functions are defined as [18]

$$
\begin{gathered}
R=\sqrt{ }\left(\frac{2}{f}\right)+2.5 \ln \left(\frac{2 e}{D_{h}}\right)+3.75 \\
e^{+}=\sqrt{ }\left(\frac{f}{2}\right) \operatorname{Re}\left(\frac{e}{D_{h}}\right) .
\end{gathered}
$$
[19]

The heat transfer function $g$ in (26a)-(26b) is defined as

$$
g=\left[\left(\frac{f}{2 S t}\right)-1\right] \sqrt{ }\left(\frac{2}{f}\right)+R .
$$

The pressure loss, from the known value of friction factor $f\left(=f_{a p p}\right.$ for smooth duct) and pumping power have been calculated from the following equations.

$$
\begin{gathered}
\delta p=\left[\frac{4 f L}{2 \rho D_{h}}\right]\left[\frac{M}{W H}\right]^{2}, \\
P=\left(\frac{M}{\rho}\right) \delta p .
\end{gathered}
$$

The thermophysical properties of the air have been taken at the corresponding mean temperature $T_{m}=T_{f m}$ or $T_{m p g}$. The following relations of the thermo-physical properties, obtained by correlating data from Holman [20], have been used:

$$
\begin{gathered}
c_{p}=1006\left(\frac{T_{m}}{293}\right)^{0.0155}, \\
k=0.0257\left(\frac{T_{m}}{293}\right)^{0.86}, \\
\mu=1.81 \times 10^{-5}\left(\frac{T_{m}}{293}\right)^{0.735}, \\
\rho=1.204\left(\frac{293}{T_{m}}\right), \\
\operatorname{Pr}=\frac{\mu c_{p}}{k} .
\end{gathered}
$$

The above set of (3) to (30) constitute a non-linear model for the solar air heater that has been used for the performance study. The model has been solved by following an iterative process presented in Figure 4. For the heat collection estimate, the iteration was terminated when the successive values of the plate and mean air temperatures differed by less than $0.05 \mathrm{~K}$, while the iteration for the estimate of top loss has been continued till the heat loss estimates from the absorber plate to the glass cover and glass cover to the ambient, that is, $Q_{\operatorname{tpg}}$ and $Q_{\text {tgo }}$ from (7a) and (7c), respectively, differed by less than $0.2 \%$.

The mathematical model presented by Karwa and Chauhan [10] was validated by Karwa et al. [11] against the data from the experimental study of a smooth duct solar air heater published in an earlier work of Karwa et al. [21] with reported uncertainties of $\pm 4.65 \%$ in Nusselt number and $\pm 4.56 \%$ in friction factor. The standard deviations of the predicted values of thermal efficiency and pumping power from the experimental values of these parameters from Karwa et al. [21] have been reported by Karwa et al. [11] to be $\pm 4.9 \%$ and $\pm 6.2 \%$, respectively.

The uncertainties in the predicted values of various parameters for the roughened duct solar collector with $60^{\circ} \mathrm{v}$ down discrete rib roughness of Karwa et al. [7] in the present work have been estimated to be $\pm 6.4 \%$ in Nusselt number, $\pm 5.9 \%$ in friction factor, $\pm 7.3 \%$ in thermal efficiency and $\pm 7.2 \%$ in pumping power.

\section{Range and Values of Various Parameters}

The range and values of the various parameters have been decided from the following considerations.

(1) The width $W$ of air heater is usually kept as $1 \mathrm{~m}$ while the length $L$ is $1-2 \mathrm{~m}$, because of the constraints of available sizes of plywood and glass sheets, ease of installation and handling, especially for individual solar air heaters sloped to face south.

(2) A low duct depth is favoured for high thermal efficiency of air heater. At flow rates $G \leq 0.045 \mathrm{kgs}^{-1} \mathrm{~m}^{-2}$, 


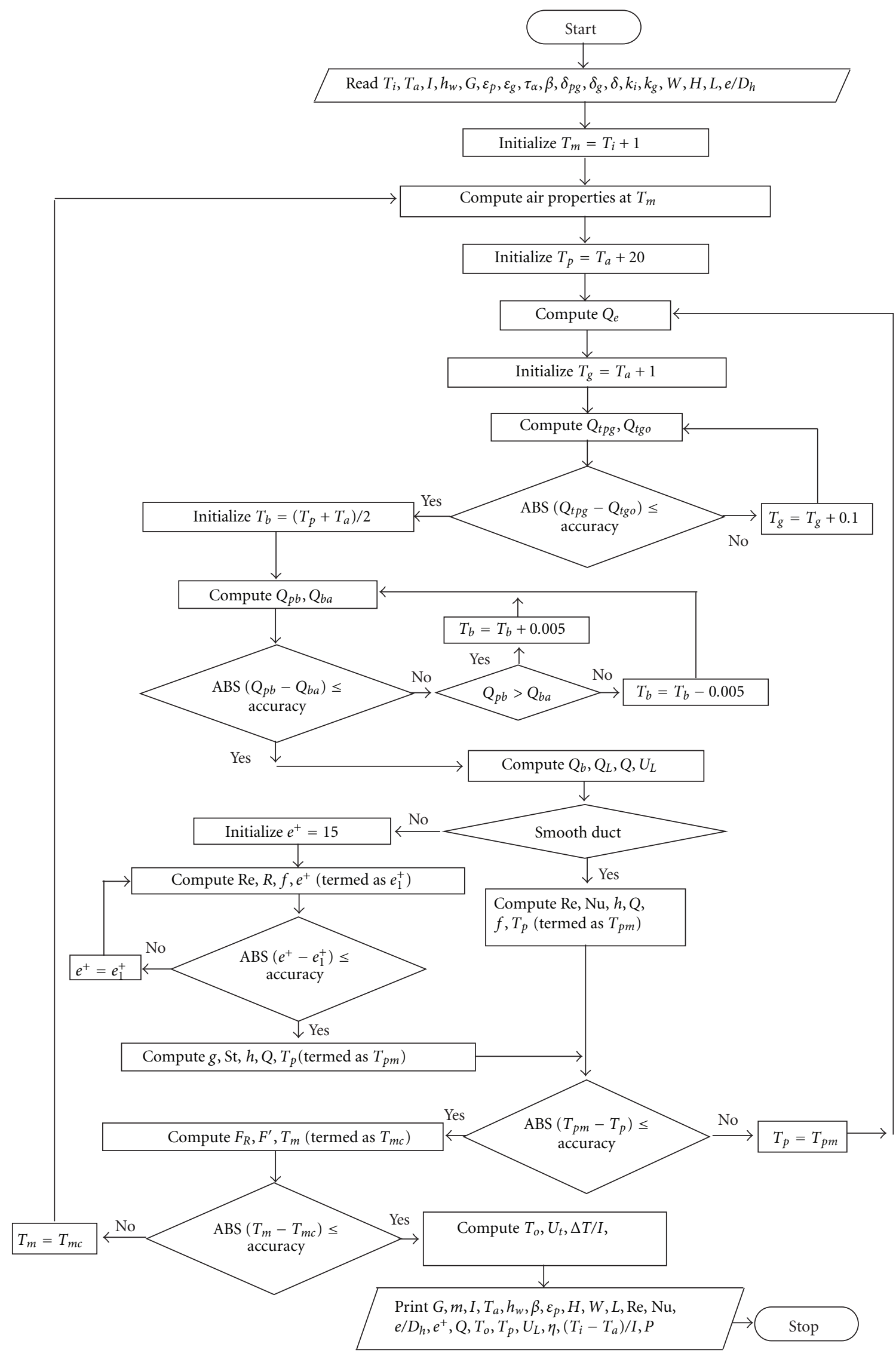

FIGURE 4: Flow chart for iterative solution of the mathematical model. 
Karwa and Chauhan [10] recommended a duct depth of $10 \mathrm{~mm}$.

(3) Low cost solar air heaters employ an absorber plate with black paint, which gives short wave emissivity of 0.95 .

(4) For maximum collection of solar energy in the winter, the collector slope $\beta$ must be about $15^{\circ}$ higher than latitude of the place. Thus, for Western Rajasthan (latitude $\approx 27^{\circ}$ ) the optimum collector slope is about $45^{\circ}$.

(5) Since the solar air heater, under discussion, is meant for space heating, the inlet temperature of the air to the collector has been taken as $295 \mathrm{~K}$ for winter operation.

(6) The ambient temperature in Western Rajasthan, especially Jodhpur, varies from $5^{\circ}-15^{\circ} \mathrm{C}$ with generally encountered minimum temperature of $8-10^{\circ} \mathrm{C}$.

(7) The wind heat transfer coefficient $h_{w}$ is a strong function of wind velocity. In Jodhpur, no wind to very mild wind condition exists in winter. The wind blows mainly from north to south. Since the collector is sloped to face south, any small variation in wind velocity will not affect the wind heat transfer coefficient significantly. Hence, the present analysis has been carried out for a fixed value of $5 \mathrm{Wm}^{-2} \mathrm{~K}^{-1}$ for the wind heat transfer coefficient.

(8) Solar radiation in Jodhpur, Rajasthan (India) varies from $500 \mathrm{Wm}^{-2}$ at 9 am to around $1000 \mathrm{Wm}^{-2}$ at the noon during a clear day in the winter on a south facing surface at $45^{\circ}$ slope. Hence, in the present analysis, the solar insolation, $I$, values have been considered to vary from 500 to $1000 \mathrm{Wm}^{-2}$.

(9) For space heating applications, a medium to high temperature rise of air is desired depending on the ambient temperature. Further, Karwa and Chauhan [10] have shown that at flow rates less than $0.045 \mathrm{kgs}^{-1} \mathrm{~m}^{-2}$, roughened collector is thermohydraulically better than smooth duct air heater. Since the ambient temperature varies in the range of $5-15^{\circ} \mathrm{C}$ in winter in Jodhpur, a mass flow rate of 0.01 to $0.045 \mathrm{kgs}^{-1} \mathrm{~m}^{-2}$ per unit area of the absorber plate has been used in the analysis.

(10) For space heating applications where flow rates are not high and pumping power is not of much concern, a solar air heater with relative roughness height of 0.07 has been used as suggested by Karwa et al. [8] and Karwa and Chauhan [10].

(11) For the air flow rate per unit area of the absorber plate, the Reynolds number in the present study ranges from about 2000 to 9000 .

The values of other collector parameters used in the analysis are listed in Table 1.

It is to note that the collector length may vary from 1 to $4 \mathrm{~m}$. However, Karwa and Chauhan [10] have shown that, if the ratio of collector length to height of the duct $(L / H)$ is

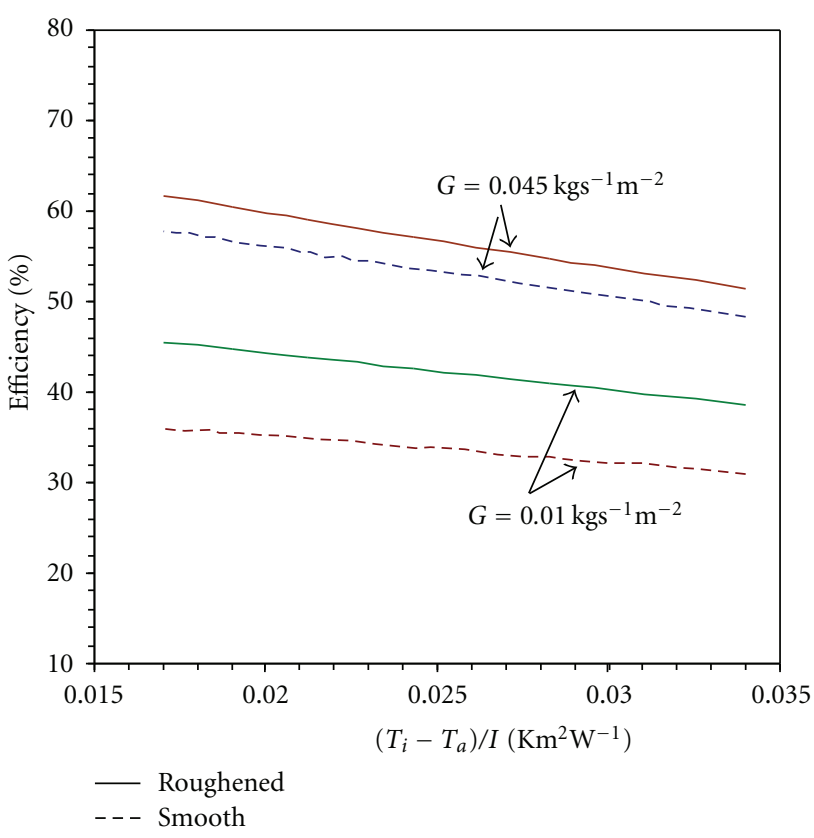

FIGURE 5: Enhancement in thermal performance due to artificial roughness $\left(L=2 \mathrm{~m}, H=10 \mathrm{~mm}, e / D_{h}=0.07, \varepsilon_{p}=0.95, \beta=45^{\circ}\right.$, $\left.T_{i}=295 \mathrm{~K}, T_{a}=278 \mathrm{~K}, h_{w}=5 \mathrm{~W} / \mathrm{m}^{2} \mathrm{~K}\right)$.

kept constant at 200, the variation in heat collection rate and hence the thermal efficiency of the collector for a given flow rate does not change significantly. Thus, the results of analysis presented here can be utilized for higher length collectors if $L / H$ is kept constant.

\section{Results and Discussion}

The comparison of the thermal efficiencies of the roughened and smooth duct solar air heaters has been presented in Figure 5. It can be seen that the artificial roughness on the absorber plate significantly improves the performance of the air heater, which is attributed to the heat transfer coefficient enhancement due to the artificial roughness on the air flow side of the absorber plate. The enhancement in the thermal efficiency is 6-26\%; the highest advantage can be seen at the lowest flow rate of $0.01 \mathrm{kgs}^{-1} \mathrm{~m}^{-2}$ of the study.

Thermal performance analysis of the roughened duct solar air heater has been carried out, using the mathematical model presented above, at three different ambient temperatures $(278 \mathrm{~K}, 283 \mathrm{~K}$, and $288 \mathrm{~K})$. The air heater operates in closed loop mode with inlet air at a constant temperature of $295 \mathrm{~K}$ from the conditioned space. The results are presented in Figures 6-8 as performance plots, wherein the thermal efficiency values have been plotted against the temperature parameter $\left[\left(T_{i}-T_{a}\right) / I\right]$ for fixed values of collector length $L=2 \mathrm{~m}$, collector width $W=1 \mathrm{~m}$, collector duct depth $H=10 \mathrm{~mm}$, absorber plate emissivity $\varepsilon_{p}=0.95$, collector slope $\beta=45^{\circ}$ and wind heat transfer coefficient $h_{w}=$ $5 \mathrm{Wm}^{-2} \mathrm{~K}^{-1}$, while air flow rate ranges from minimum of 0.01 to the maximum of $0.045 \mathrm{kgs}^{-1}$ per $\mathrm{m}^{2}$ of the absorber plate. 
TABLE 1: Values of parameters.

\begin{tabular}{ll}
\hline Parameter & Value \\
\hline Absorber plate-glass cover transmittance absorptance product, $\tau \alpha$ & 0.8 (fixed) for single glass cover \\
Gap between the absorber plate and glass cover, $\delta_{p g}$ & $40 \mathrm{~mm}$ \\
Insulation & Foamed polystyrene or glass wool \\
Thermal conductivity of insulation, $k_{i}$ & $0.037 \mathrm{Wm}^{-1} \mathrm{~K}^{-1}$ \\
Insulation thickness, $\delta$ & $50 \mathrm{~mm}^{\text {Long wave emissivity of glass cover, } \varepsilon_{g}}$ \\
\hline
\end{tabular}

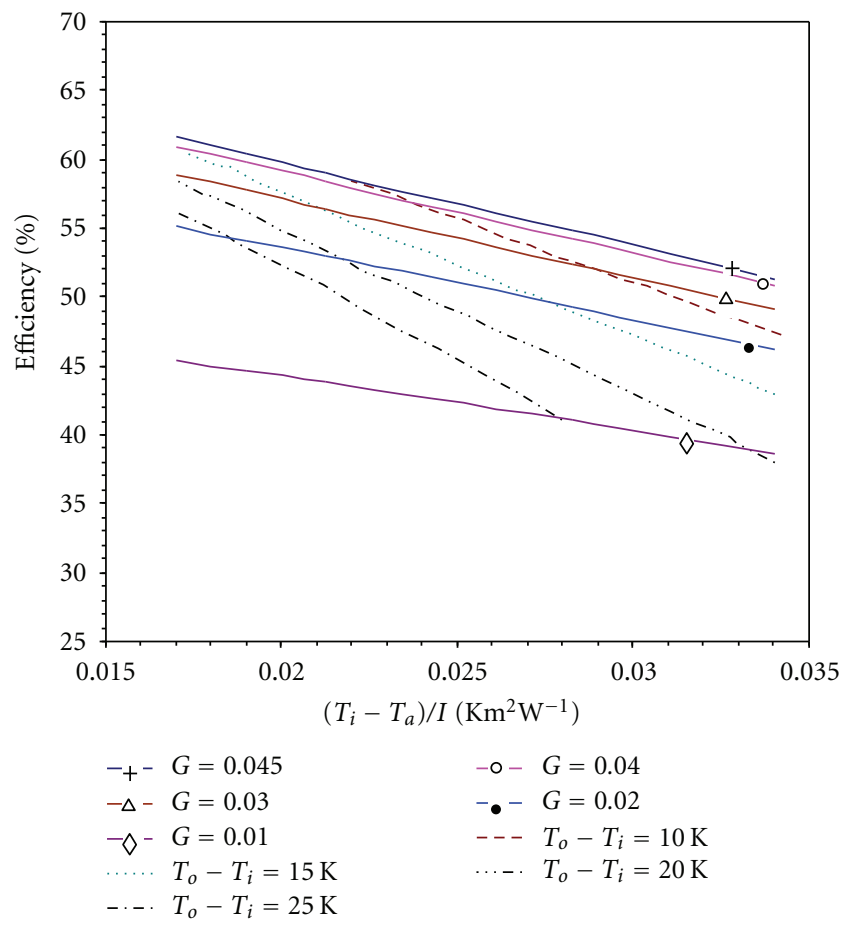

FIGURE 6: Thermal efficiency of roughened solar air heater as function of temperature parameter $\left(T_{i}-T_{a}\right) / I$ at $T_{a}=278 \mathrm{~K}$ $\left(L=2 \mathrm{~m}, H=10 \mathrm{~mm}, e / D_{h}=0.07, \varepsilon_{p}=0.95, \beta=45^{\circ}, T_{i}=295 \mathrm{~K}\right.$, $\left.h_{w}=5 \mathrm{~W} / \mathrm{m}^{2} \mathrm{~K}\right)$.

5.1. Variation of Thermal Efficiency with Flow Rate. It is worth noting that the flow rate is basically decided from the rise of the temperature of the air desired for a particular application. In the case of space heating applications, a constant temperature rise of the air may be desired.

Looking to the above mentioned basic requirement of constant temperature rise of the air for the space heating applications, lines of constant temperature rise $\left(T_{o}-T_{i}\right)=$ $10^{\circ} \mathrm{C}, 15^{\circ} \mathrm{C}, 20^{\circ} \mathrm{C}$, and $25^{\circ} \mathrm{C}$ have also been plotted in Figures $6-8$. From the study of constant temperature rise lines, it can be seen that, as the solar insolation increases, parameter $\left(T_{i}-T_{a}\right) / I$ decreases and the air flow rate must increase, and vice versa. Thus, from the morning (around $9 \mathrm{am}$ ) to noon, the flow rate must increase with the increase in solar insolation and, then, must decrease from its maximum value in the noon again to the lowest value at around 4:30 pm.
From the constant temperature lines in the performance plots, the required flow rate for a given temperature parameter value can be estimated from the plots. A correct value of the mass flow rate per unit area of the absorber plate can be determined as explained below.

Let $T_{a}=283 \mathrm{~K}$ and solar insolation $I$ is $800 \mathrm{Wm}^{-2}$. The desired temperature rise of the air $\left(T_{o}-T_{i}\right)$ is $15 \mathrm{~K}$. Then, for $T_{i}=295 \mathrm{~K},\left(T_{i}-T_{a}\right) / I$ equals 0.015 . A vertical line, as shown in Figure 7, cuts the $\left(T_{o}-T_{i}\right)=15 \mathrm{~K}$ line at thermal efficiency $\eta$ of $59.2 \%$. From which, the mass flow rate per unit area of plate $G$ is calculated as:

$$
G=\frac{\eta I}{\left[c_{p}\left(T_{o}-T_{i}\right)\right]}=\frac{0.592 \times 800}{(1005 \times 15)}=0.0314 \mathrm{~kg} \mathrm{~s}^{-1} \mathrm{~m}^{-2} .
$$

5.2. Effect of Ambient Temperature on Thermal Efficiency. Comparison of the performance plots in Figures 6-8 shows that the thermal efficiency increases with the rise in the ambient temperature. The analysis shows that, with change in the ambient temperature from $278 \mathrm{~K}$ to $288 \mathrm{~K}$, the efficiency increases by $7.5 \%$ when solar radiation intensity is $500 \mathrm{Wm}^{-2}$, while the increase in the efficiency is $17.8 \%$ when $I=$ $1000 \mathrm{Wm}^{-2}$. This can be attributed to the fact that with the rise in the ambient temperature the heat loss from the collector reduces because of a lower temperature excess (plate temperature-ambient temperature).

5.3. Thermo-Hydraulic Performance. The requirement of the pumping power as fraction of the heat collection rate at the highest and the lowest solar insolation values is shown in Figure 9 as function of the mass flow rate of the air through the collector duct per unit area of the absorber plate. At the highest flow rate of $G=0.045 \mathrm{kgs}^{-1} \mathrm{~m}^{-2}$ and the lowest solar insolation $I$ of $500 \mathrm{Wm}^{-2}$ in the study, the pumping power is about $5.5 \%$ of the heat collection rate but this is not of much concern because at the low values of the solar insolation the flow rate is also kept low to achieve a reasonable rise of the temperature of the air. It reduces to about $2.4 \%$ when $I=1000 \mathrm{Wm}^{-2}$ at the same flow rate because of the greater heat collection rate. With the decrease in the flow rate $G$, the required pumping power decreases drastically. For example, at $G=0.01 \mathrm{kgs}^{-1} \mathrm{~m}^{-2}$ and $I=500 \mathrm{Wm}^{-2}$, the pumping power is less than $0.1 \%$ of the heat collection rate and is only $0.045 \%$ of the heat collection rate when solar insolation is $1000 \mathrm{Wm}^{-2}$. Thus, in the case of solar air heater 


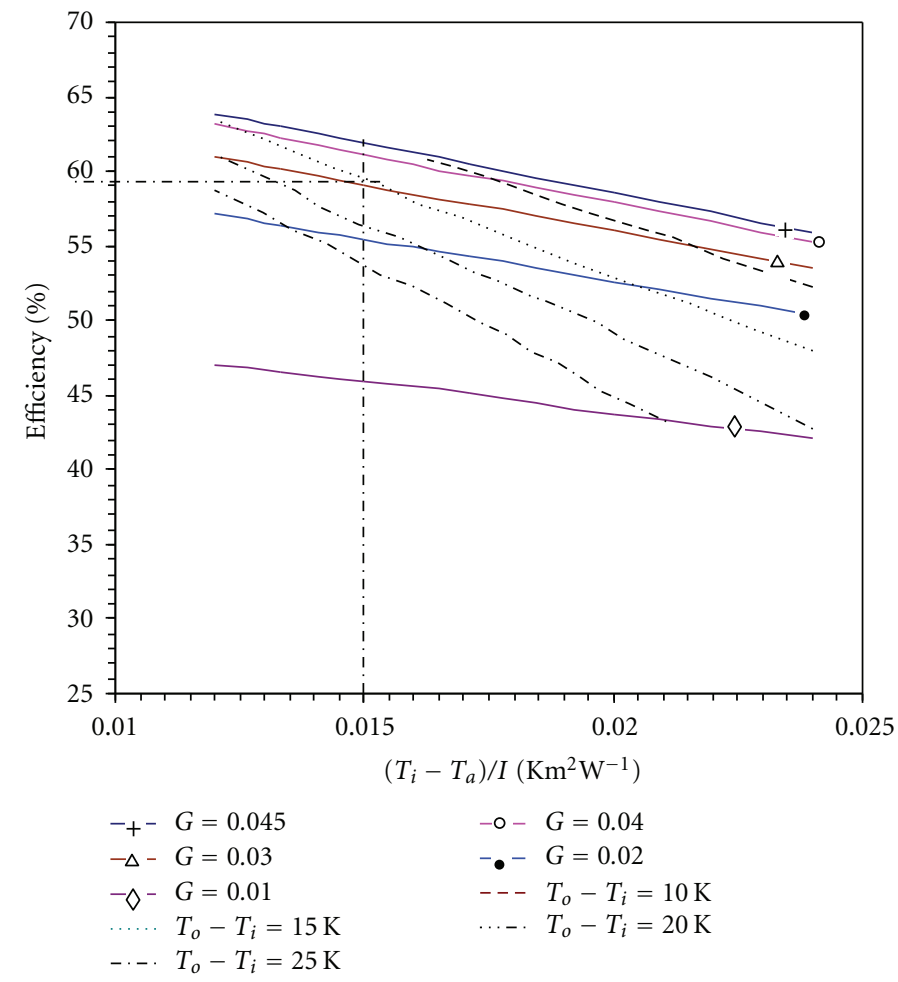

FIGURE 7: Thermal efficiency of roughened solar air heater as function of temperature parameter $\left(T_{i}-T_{a}\right) / I$ at $T_{a}=283 \mathrm{~K}(L=2 \mathrm{~m}$, $\left.H=10 \mathrm{~mm}, e / D_{h}=0.07, \varepsilon_{p}=0.95, \beta=45^{\circ}, T_{i}=295 \mathrm{~K}, h_{w}=5 \mathrm{~W} / \mathrm{m}^{2} \mathrm{~K}\right)$.

for space heating applications, the pumping power is not of much concern, that is, the thermo-hydraulic performance defined by (2) is not significantly different from the thermal efficiency except at the flow rate $G \geq 0.04 \mathrm{kgs}^{-1} \mathrm{~m}^{-2}$. Hence, the plots of the effective efficiency $\eta_{e}$ have not been drawn in the presented performance plots.

\section{Conclusions}

Thermal performance analysis of a solar air heater with vdown discrete rib roughness has been carried out using a mathematical model. The collector, which supplies heated air for space heating application, is installed at a slope of $45^{\circ}$ facing south and operates in a closed loop mode with inlet air at a fixed temperature of $295 \mathrm{~K}$ from the conditional space in winter season of Western Rajasthan, India. The ambient temperature has been varied from $278 \mathrm{~K}$ to $288 \mathrm{~K}$. The important observations of the study are as follows.

(1) The thermal efficiency of the roughened duct air heater is $6-26 \%$ higher than that of a smooth duct air heater; the highest advantage is at the lowest flow rate of $0.01 \mathrm{kgs}^{-1} \mathrm{~m}^{-2}$ of the study.

(2) The mass flow rate of air per unit area of absorber plate needs to be varied according to the variation in the solar insolation during the day for constant temperature rise of air through the collector and greater overall heat collection.

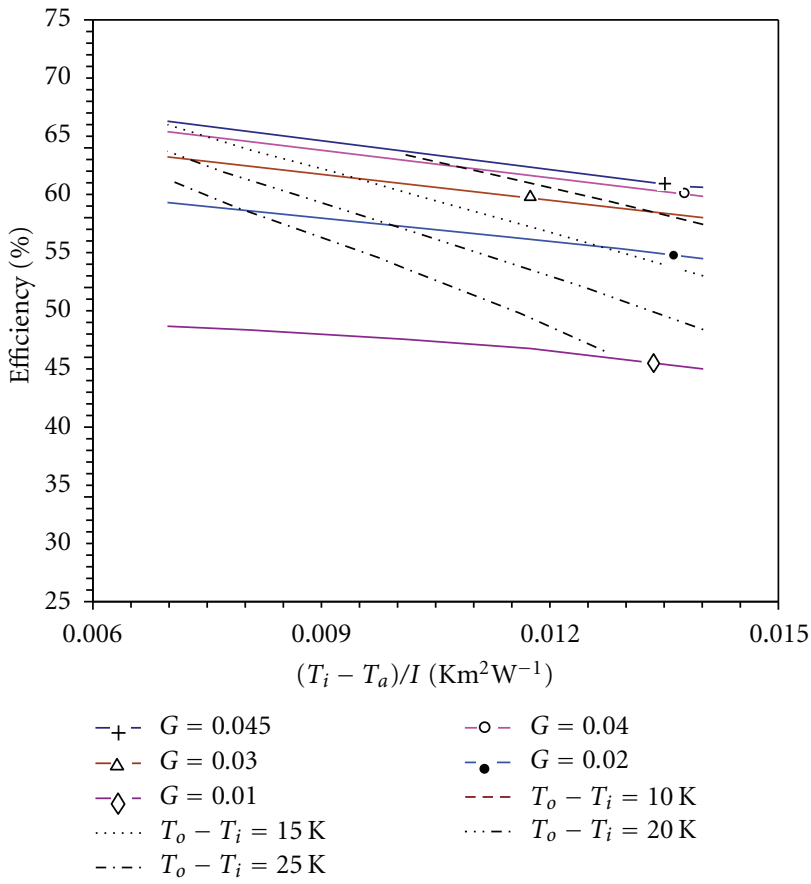

FIgURE 8: Thermal efficiency of roughened solar air heater as function of temperature parameter $\left(T_{i}-T_{a}\right) / I$ at $T_{a}=288 \mathrm{~K}$ $\left(L=2 \mathrm{~m}, H=10 \mathrm{~mm}, e / D_{h}=0.07, \varepsilon_{p}=0.95, \beta=45^{\circ}, T_{i}=295 \mathrm{~K}\right.$, $\left.h_{w}=5 \mathrm{~W} / \mathrm{m}^{2} \mathrm{~K}\right)$. 


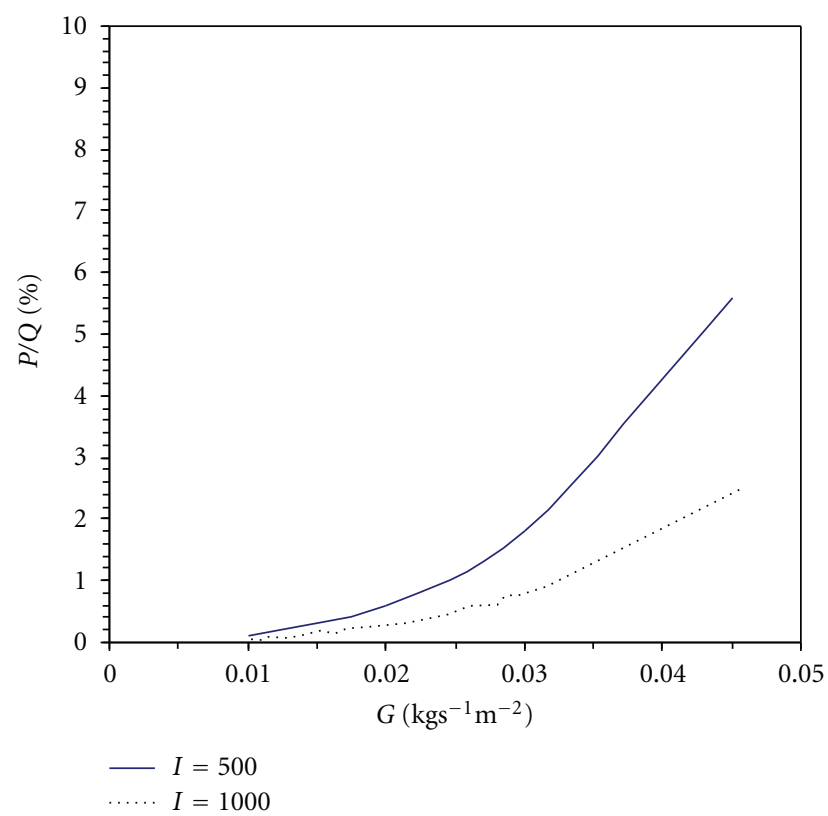

FIGURE 9: Pumping power as percentage of the heat collection rate.

(3) With the increase in the ambient temperature from $278 \mathrm{~K}$ to $288 \mathrm{~K}$, the thermal efficiency increases by $7.5 \%$ to $17.8 \%$, increasing with solar insolation.

(4) The pumping power requirement is not of concern at low flow rates. At the highest flow rate of $G=$ $0.045 \mathrm{kgs}^{-1} \mathrm{~m}^{-2}$ and the highest value of the solar insolation $I=1000 \mathrm{Wm}^{-2}$, it is the maximum and is of the order of $2.4 \%$ of the heat collection rate.

The results of analysis are presented in the form of performance plots with constant temperature rise lines of $10^{\circ} \mathrm{C}, 15^{\circ} \mathrm{C}, 20^{\circ} \mathrm{C}$, and $25^{\circ} \mathrm{C}$, which can be utilized by the designer for calculating desired air flow rate under different operating conditions.

\section{Nomenclature}

A: $\quad$ Area of absorber plate, $\mathrm{m}^{2}$

$B$ : $\quad$ Half length of a full $\mathrm{v}$-rib element, $\mathrm{m}$

$B / S$ : Relative roughness length of discrete ribs

$c_{p}: \quad$ Specific heat of air, $\mathrm{J}^{\mathrm{kg}}{ }^{-1} \cdot \mathrm{K}^{-1}$

$D_{h}$ : Equivalent diameter of duct $=4 W H /[2(W+H)], \mathrm{m}$

$e: \quad$ Rib height, $\mathrm{m}$

$e / D_{h}$ : Relative roughness height

$e^{+}: \quad$ Roughness Reynolds number

$f: \quad$ Friction factor

$g:$ Heat transfer function

G: $\quad$ Mass flow rate per unit area of absorber plate, $\mathrm{kg} \cdot \mathrm{s}^{-1} \cdot \mathrm{m}^{-2}$

$\begin{array}{ll}h: & \text { Heat transfer coefficient, } \mathrm{W} \cdot \mathrm{m}^{-2} \cdot \mathrm{K}^{-1} \\ h_{w}: & \text { Wind Heat transfer coefficient, } \\ & \mathrm{W} \cdot \mathrm{m}^{-2} \cdot \mathrm{K}^{-1} \\ H: & \text { Height of duct, } \mathrm{m} \\ I: & \text { Solar insolation, } \mathrm{W} \cdot \mathrm{m}^{-2} \\ K: & \text { Thermal conductivity of air, } \\ & \mathrm{W} \cdot \mathrm{m}^{-1} \cdot \mathrm{K}^{-1} \\ l / e: & \text { Relative longway length of mesh } \\ L: & \text { Length of collector, } \mathrm{m} \\ M: & \text { Mass flow rate, } \mathrm{kg} \cdot \mathrm{s}^{-1} \\ m: & \text { Mass velocity of air }=(\mathrm{M} / \mathrm{WH}), \\ & \text { kg.s } \mathrm{s}^{-1} \cdot \mathrm{m}^{-2} \\ \mathrm{Nu}: & \text { Nusselt number } \\ p: & \text { Rib pitch, } \mathrm{m} \\ P: & \text { Pumping power, } \mathrm{W} \\ p / e: & \text { Relative roughness pitch } \\ \mathrm{Pr}: & \text { Prandtl number } \\ \mathrm{Q}: & \text { Heat collection rate, } \mathrm{W} \\ R: & \text { Roughness function } \\ \mathrm{Re}: & \text { Reynolds number } \\ s: & \text { Shortway length of mesh, } \mathrm{m} \\ s / e: & \text { Relative shortway length of mesh } \\ S: & \text { Length of a discrete rib element, } \mathrm{m} \\ \mathrm{St}: & \text { Stanton number }=\mathrm{Nu} /(\mathrm{Re} \text { Pr }) \\ T_{a}: & \text { Ambient temperature, } \mathrm{K} \\ T_{f m}, T_{m}: & \text { Mean air temperature }=\left(T_{o}+T_{i}\right) / 2, \mathrm{~K} \\ T_{i}: & \text { Inlet air temperature, } \mathrm{K} \\ T_{m p g}: & \text { Mean of the plate and glass } \\ & \text { temperatures }=\left(T_{p}+T_{g i}\right) / 2, \mathrm{~K} \\ T_{o}: & \text { Outlet air temperature, } \mathrm{K} \\ T_{p}: & \text { Mean plate temperature, } \mathrm{K} \\ T_{s}: & \text { Sky temperature, } \mathrm{K} \\ U_{\mathrm{L}}: & \text { Overall loss coefficient, Wm }{ }^{-2} \mathrm{~K}^{-1} \\ W: & \text { Width of duct, } \mathrm{m} . \\ & \end{array}$

Greek Symbols

$\alpha: \quad$ Angle of attack, degree

$\beta$ : $\quad$ Collector slope, degree

$\delta_{p g}:$ Gap between the absorber plate and glass cover, $\mathrm{m}$

$\Delta T: \quad$ Temperature rise of air, ${ }^{\circ} \mathrm{C}$

$\eta: \quad$ Thermal efficiency of collector

$\varepsilon: \quad$ Emissivity

$v_{m p g}:$ Kinematic viscosity of air at temperature $T_{m p g}, \mathrm{~m}^{2} / \mathrm{s}$

$\tau \alpha: \quad$ Transmittance-absorptance product

$\phi: \quad$ Chamfer angle, wedge angle, degree

$\mu$ : Dynamic viscosity of air, Pa.s.

Subscripts

$b$ : Duct bottom surface

$g$ : Glass

$m$ : Mean

$p$ : Plate

$s$ : Smooth. 


\section{References}

[1] D. Gupta, S. C. Solanki, and J. S. Saini, "Heat and fluid flow in rectangular solar air heater ducts having transverse rib roughness on absorber plates," Solar Energy, vol. 51, no. 1, pp. 31-37, 1993.

[2] D. Gupta, S. C. Solanki, and J. S. Saini, "Thermohydraueic performance of solar air heaters with roughened absorber plates," Solar Energy, vol. 61, no. 1, pp. 33-42, 1997.

[3] R. P. Saini and J. S. Saini, "Heat transfer and friction factor correlations for artificially roughened ducts with expanded metal mesh as roughness element," International Journal of Heat and Mass Transfer, vol. 40, no. 4, pp. 973-986, 1997.

[4] R. Karwa, S. C. Solanki, and J. S. Saini, "Heat transfer coefficient and friction factor correlations for the transitional flow regime in rib-roughened rectangular ducts," International Journal of Heat and Mass Transfer, vol. 42, no. 9, pp. 1597-1615, 1999.

[5] J. L. Bhagoria, J. S. Saini, and S. C. Solanki, "Heat transfer coefficient and friction factor correlations for rectangular solar air heater duct having transverse wedge shaped rib roughness on the absorber plate," Renewable Energy, vol. 25, no. 3, pp. 341-369, 2002.

[6] A. M. Ebrahim Momin, J. S. Saini, and S. C. Solanki, "Heat transfer and friction in solar air heater duct with V-shaped rib roughness on absorber plate," International Journal of Heat and Mass Transfer, vol. 45, no. 16, pp. 3383-3396, 2002.

[7] R. Karwa, R. D. Bairwa, B. P. Jain, and N. Karwa, "Experimental study of the effects of rib angle and discretization on heat transfer and friction in an asymmetrically heated rectangular duct," Journal of Enhanced Heat Transfer, vol. 12, no. 4, pp. 343-355, 2005.

[8] R. Karwa, A. Sharma, and N. Karwa, "A comparative study of different roughness geometries proposed for solar air heater ducts," International Review of Mechanical Engineering, vol. 4, no. 2, pp. 159-166, 2010.

[9] R. Karwa, "Experimental studies of augmented heat transfer and friction in asymmetrically heated rectabgular ducts with ribs on the heated wall in transverse, inclined, $v$-continous and v-discrete pattern," International Communications in Heat and Mass Transfer, vol. 30, no. 2, pp. 241-250, 2003.

[10] R. Karwa and K. Chauhan, "Performance evaluation of solar air heaters having $\mathrm{v}$-down discrete rib roughness on the absorber plate," Energy, vol. 35, no. 1, pp. 398-409, 2010.

[11] R. Karwa, N. Karwa, R. Misra, and P. C. Agarwal, "Effect of flow maldistribution on thermal performance of a solar air heater array with subcollectors in parallel," Energy, vol. 32, no. 7, pp. 1260-1270, 2007.

[12] S. A. Klein, "Calculation of flat-plate collector loss coefficients," Solar Energy, vol. 17, no. 1, pp. 79-80, 1975.

[13] W. C. Swinbank, "Long-wave radiation from clear skies," Quarterly Journal of the Royal Meteorological Society, vol. 89, pp. 339-348, 1963.

[14] H. Buchberg, I. Catton, and D. K. Edwards, "Natural convection in enclosed spaces - a review of application to solar energy collection," Journal of Heat Transfer, vol. 98, no. 2, pp. 182-188, 1976.

[15] M. A. Ebadian and Z. F. Dong, "Forced convection, internal flow in ducts," in Handbook of Heat Transfer, W. M. Rohsenow, J. P. Hartnett, and Y. I. Cho, Eds., McGraw-Hill, New York, NY, USA, 1998.

[16] K. G. T. Hollands and E. C. Shewen, "Optimization of flow passage geometry for air-heating, plate-type solar collectors,"
Journal of Solar Energy Engineering, vol. 103, no. 4, pp. 323-330, 1981.

[17] M. S. Bhatti and R. K. Shah, "Turbulent and transition flow convective heat transfer," in Handbook of Single-Phase Convective Heat Transfer, S. Kakac, R. K. Shah, and W. Aung, Eds., Wiley, New York, NY, USA, 1987.

[18] J. Nikuradse, "Laws of flow in rough pipes," Technical Memorandum 1292, NACA, 1950.

[19] D. F. Dipprey and R. H. Sabersky, "Heat and momentum transfer in smooth and rough tubes at various prandtl numbers," International Journal of Heat and Mass Transfer, vol. 6, no. 5, pp. 329-353, 1963.

[20] J. P. Holman, Heat Transfer, McGraw-Hill, New York, NY, USA, 7th edition, 1990.

[21] R. Karwa, S. C. Solanki, and J. S. Saini, "Thermo-hydraulic performance of solar air heaters having integral chamfered rib roughness on absorber plates," Energy, vol. 26, no. 2, pp. 161-176, 2001. 


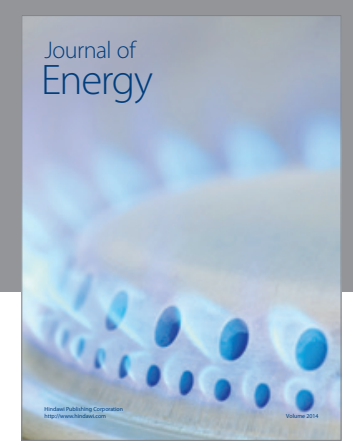

Journal of

Industrial Engineering
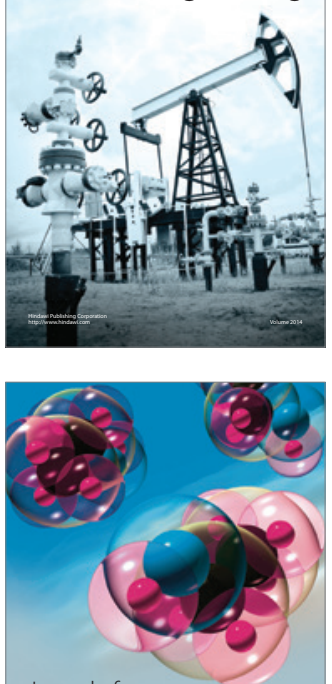

Fuels
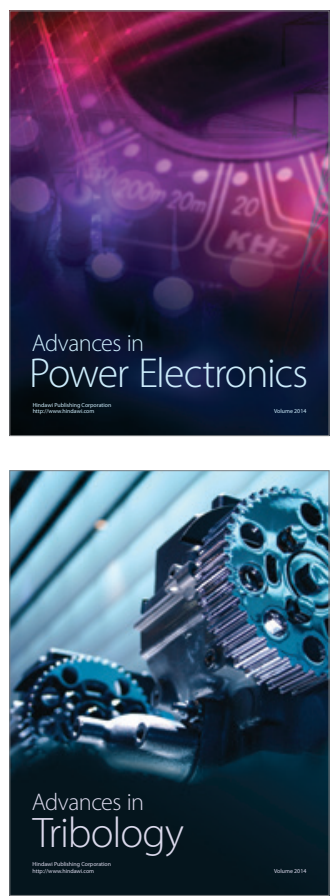

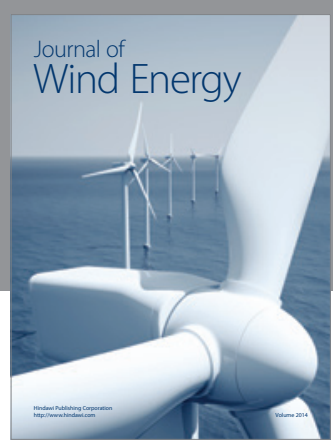

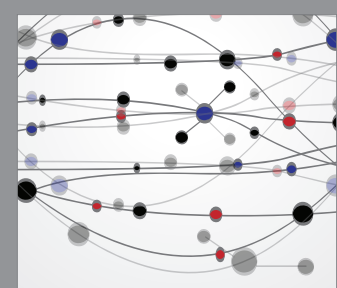

The Scientific World Journal

Submit your manuscripts at http://www.hindawi.com

Journal of

Structures
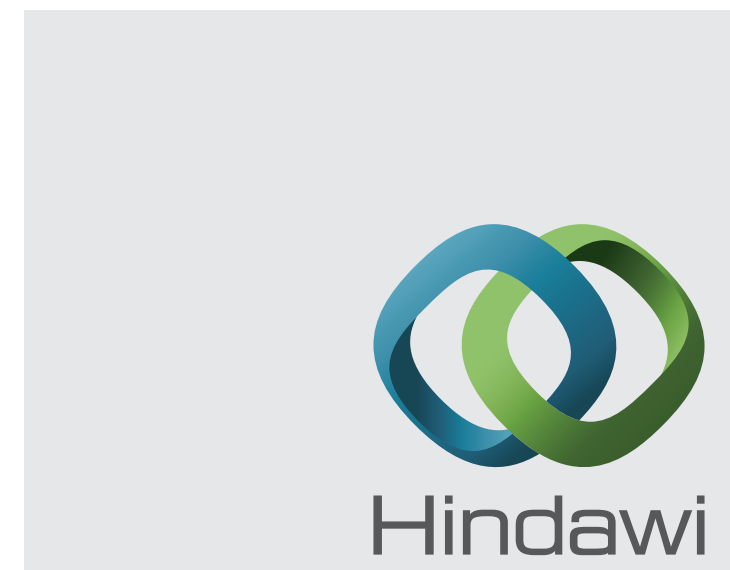

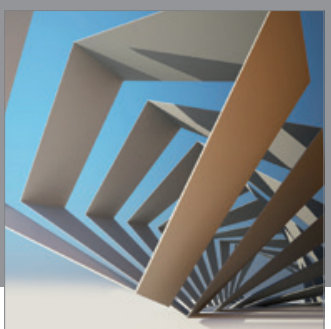

Rotating

Machinery
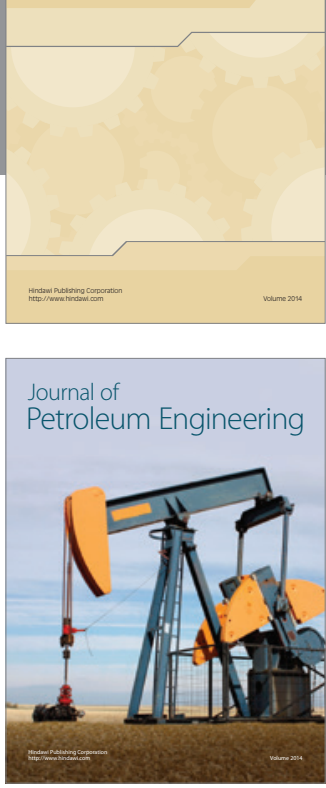

Journal of

Solar Energy
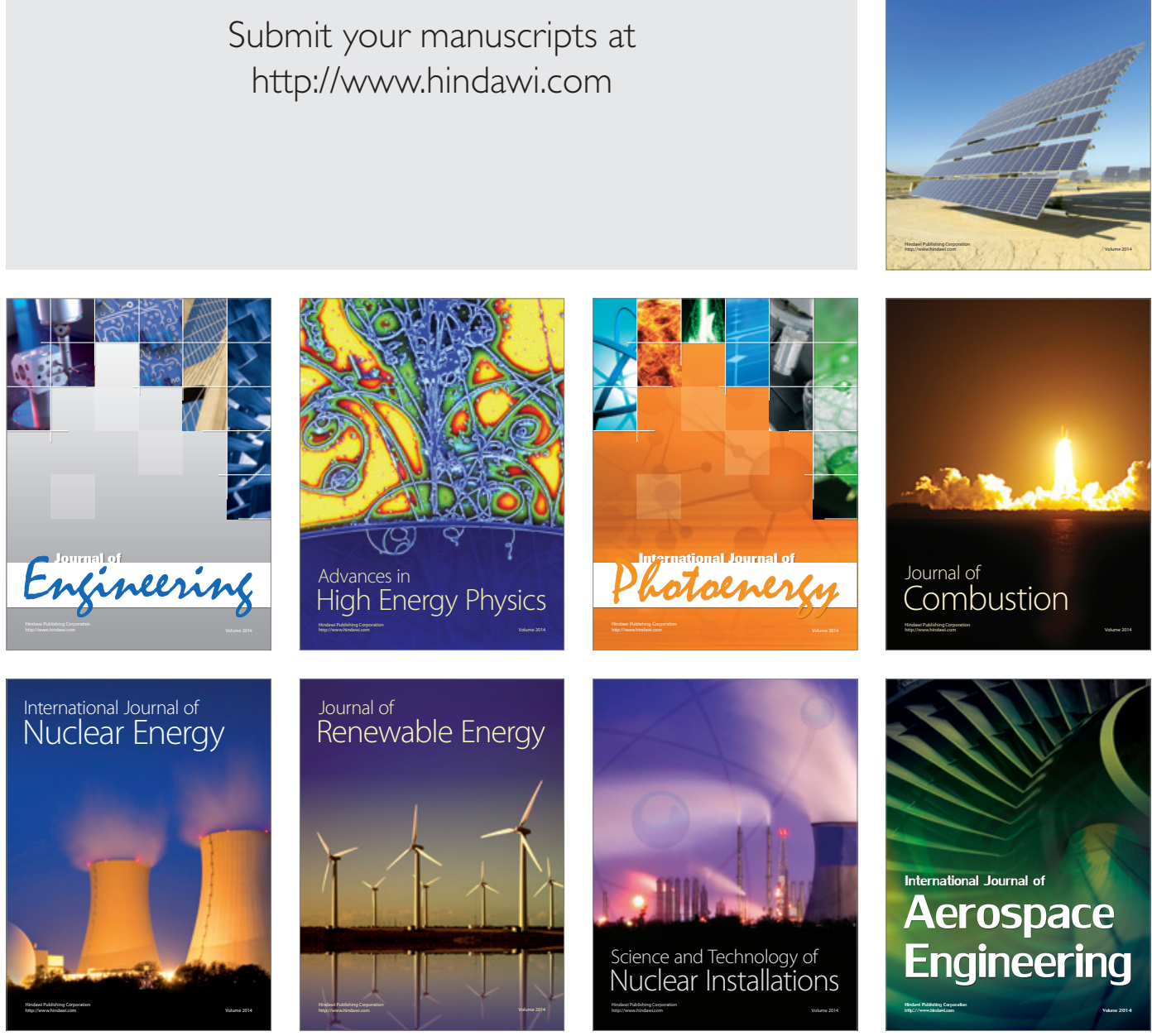